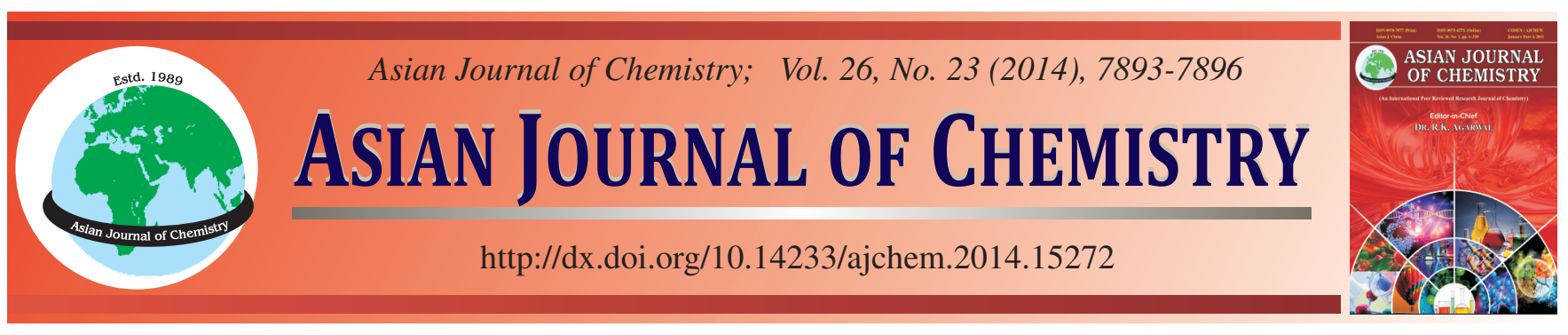

\title{
Identification and Quantification of Polycyclic Aromatic Hydrocarbons in Tehran Drinking Water by Gas Chromatography-Mass Spectrometry
}

\author{
Mahtab Baghban $^{1}$, Saeid Mansour Baghahi $^{1}$, Fatemeh Damercheli $^{2}$ and Ali Akbar Miran Beigi ${ }^{3, *}$
}

${ }^{1}$ Tehran Province Water and Wastewater Research Group, Tehran, Iran

${ }^{2}$ Iran Mineral Processing Research Center, Tehran, Iran

${ }^{3}$ Oil Refining Research Division, Research Institute of Petroleum Industry, Tehran, Iran

*Corresponding author: Fax: +98 21 44739738; Tel: +98 21 48255042; E-mail: miranbeigiaa@ ripi.com; amiranbeigi@yahoo.com

Received: 4 November 2013;

Accepted: 18 March 2014;

Published online: 15 November 2014;

AJC-16258

\begin{abstract}
Polycyclic aromatic hydrocarbons are a main group of organic compounds that their monitoring in water recourses is very important because of their side effects such as carcinogenic, genetic and systematic effects on human health. Sources of water pollution with polycyclic aromatic hydrocarbons are oil industries, oil leakage from storage tanks and oil transferring pipe lines, using of fossil fuels, industrial wastewater's disposal, burning and ash of wastes, etc. Due to ecological and environmental importance and also vast spreading of the pollutant resources in many districts of Iran including, monitoring of pollutants is necessary especially in Tehran province in order to ensure the health of water resources. In this study, 16 compounds of polycyclic aromatic hydrocarbons which are listed as potentiallycarcinogen agents for human by the United States Environmental Protection Agency (EPA) were determined by gas chromatographymass spectrometry. The instrument was calibrated in a selected ion monitoring mode (SIM mode) and it was equipped to a $30 \mathrm{~m}$ capillary column. In this research five water effluents including Jalalieh, Kan, Tehranpars 1, Tehranpars 2 and Sohanak water treatment plants with several water storage tanks (related to Tehran province water distribution) were studied. The samples were extracted from liquid phase and analyzed by injection to a GC-MS system (Agilent $6890 \mathrm{~N}$ ). The mass spectra indicate that the concentrations of these 16 polycyclic aromatic hydrocarbons compounds are lower than permitted limits of Iranian National Standard (standard number 1053 for drinking water), World Health Organization (WHO) and US.EPA recommendations.
\end{abstract}

Keywords: Polycyclic aromatic hydrocarbons, Water storage tanks, Gas chromatography-mass spectrometry, Drinking water.

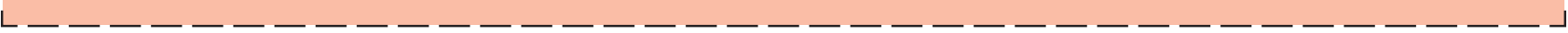

\section{INTRODUCTION}

Tehran province drinking water is providing via many different recourses include surface water resources (Jajrood and Karaj rivers, ended rivers to Lar dam) and underground water resources (deep and semi-deep wells). Since, the population of Tehran province has high growth and disproportion between the growth of population and very limited amounts of renewable water resources, it is necessary to monitor and control the quality of drinking water from resources to consumption points based on quality standards.

Polycyclic aromatic hydrocarbons (PAHs) are a group of carbon compounds include polynuclear aromatics (PNAs), arenes and poly arenes. There are 1896 possible structures for polycyclic aromatic hydrocarbons that have 2-8 aromatic or non-aromatic cycles that are primarily released into the environment by the incomplete combustion of fossil fuels and the burning of vegetation and other organic materials ${ }^{1-4}$. These compounds started from naphthalene with 2 cycles and ended to Cronin with 7 cycles. The most dangerous compound in the list is benzo(a)pyrene which has 7 diffused cycles. The other polycyclic aromatic hydrocarbons that recognized as a carcinogen, is the 4 cycle hydrocarbon, benzo(a)anthracenes. In literature it was found that there is a relationship between polycyclic aromatic hydrocarbons concentration and skin and gastrointestinal tumors, liver and esophagus cancers. A linear poly stage model was used to risk assessment for this purpose. This model defines the acceptable risk as 1 of 100,000.

The US.EPA defined 16 PAH compounds which are marked with a $*$ sign in Fig. 1, as primary pollutants ${ }^{5}$. The European Union defines the compounds that shown by $\mp$ sign as necessary compounds to monitoring ${ }^{6}$. The Florentine is recently added to the list ${ }^{7}$. Polycyclic aromatic hydrocarbons are produced via imperfect combustion of fossil fuels, burning and ash the wastes, industrial activities and etc. and also via synthesis by some bacteria, alga and coalescent plants ${ }^{8}$.

In industrial countries, $35 \%$ of polycyclic aromatic hydrocarbons entered to the environment from vehicles exhaust 
and fuel leakage. These compounds produced when cooking foods, specially meet fried or barbequed in high temperatures ${ }^{9}$. Some materials like asphalt ${ }^{10}$, creosote and wood conservatives have lots of polycyclic aromatic hydrocarbons ${ }^{11}$. In the nature, polycyclic aromatic hydrocarbons are in homo cyclic and hetero cyclic derivations such as sulfur, oxygen and nitrogen contain heterocycles.

Polycyclic aromatic hydrocarbons have a low solubility in water but they rapidly adsorbed to mud, sludge and micro particles, their concentration in the water is too higher than their solubility range. This components decomposed by UV irradiation (emitted by sunshine) and some soil microorganisms ${ }^{12,13}$. These compounds adsorbed by aspiratory system, gastrointestinal system and skin in human. They have many side effects system, gastrointestinal system and skin in human. They have many side effects such as carcinogenic, genetic, systematic and lethal effects ${ }^{14,15}$. Hence, it is necessary to study these pollutants and their monitoring in Tehran and urban water resources. In this research ${ }^{16}$, polycyclic aromatic hydrocarbons compounds include: naphthalene, acenaphtha-lene, fluorene, phenanthrene, anthracene, fluorantene, pyrene, benzo(a)anthracene, chrycene, benzo(b)fluoranthene, benzo(k)fluoranthene, benzo(a)pyrene, indeno(1,2,3-cd)pyrene, dibenzo(a,h)anthracene and benzo(g,h,i)perylene, were studied and the analytical results compared with Iranian national standard (standard no. 1053 for drinking water), world health organization (WHO) and US. EPA recommendations. The method was ideally suited for determination of the investigated polycyclic aromatic hydrocarbons in drinking water. The method was free from presence of interferences such as halogenated and unsaturated hydrocarbons. Here various instrumental conditions were optimized. Under optimal conditions, the $3 \mathrm{~s}$ averaged detection limit was $4.5 \mathrm{ng} \mathrm{L}^{-1}$. At $15 \mathrm{ng} \mathrm{L}^{-1}$ the relative standard deviations $(\mathrm{n}=4)$ was less than $2.7 \%$.

\section{EXPERIMENTAL}

In this study, samples were prepared from outlet of Tehran water treatment plants, high capacity storage tanks and some places in distribution network. Clean glass bottles with capacity of $500 \mathrm{~mL}$ were used to sampling and transferring or storage of the samples. All samples conserved by $10 \mathrm{~mL}$ of a mixture of hexane and dichloromethane (6:4 ratio by volume). The extraction technique was liquid-liquid extraction (L.L.E). The extraction performed in two stages by hexane solvent (because of low solubility of polycyclic aromatic hydrocarbons, it is possible to use $\mathrm{NaCl}$ as an extractant to organic phase). Hexane solvent and extracted analyte concentrated to $1 \mathrm{~mL}$ in a rotary evaporator. Then the sample volume reduced to $0.5 \mathrm{~mL}$ via preconcentration by pure nitrogen gas (according to 610 and 3510c US.EPA methods $)^{17,18}$. A gas chromatograph-mass spectrometer (GC-MS) was used for qualitative and quantitative determination of 16 polycyclic aromatic hydrocarbons compounds in the real samples. Total ion current chromatograms were acquired and processed using Workstation data analysis software. To increase sensitivity, the selected ion monitoring (SIM) mode was applied in quantitative analysis. The most abundant ion was used as the quantified ion. All GC-MS quantifications made in this study were based on the relative peak area of analytes to the internal standard from the average of three replicate measurements.

\section{RESULTS AND DISCUSSION}

In order to optimize the controllable parameters, pyrene was used as the internal standard. A list of various instrumental conditions was summarized in Table-1.

\section{TABLE-1}

TYPICAL INSTRUMENTAL PARAMETERS FOR THE

DETERMINATION OF THE INVESTIGATED POLYCYCLIC

AROMATIC HYDROCARBONS IN DRINKING WATERS

\begin{tabular}{|c|c|}
\hline Condition & Value \\
\hline Injector technique & Splitless \\
\hline Injector temperature & $290^{\circ} \mathrm{C}$ \\
\hline Injection volume & $3 \mu \mathrm{L}$ \\
\hline Carrier gas & Helium \\
\hline Flow rate & $1 \mathrm{~mL} \mathrm{~min}^{-1}$ \\
\hline Aux. temperature & $290^{\circ} \mathrm{C}$ \\
\hline Detection mode & SIM \\
\hline Column & $\begin{array}{l}30 \mathrm{~m} \text { Length, } 0.25 \mathrm{~mm} \text { Diameter, } \\
\text { Film thickness; } 0.5 \mu \mathrm{m} \text {, Phase; DB5-MS }\end{array}$ \\
\hline \multicolumn{2}{|l|}{ Temperature program } \\
\hline Initial temp. & $60{ }^{\circ} \mathrm{C}$ \\
\hline Isothermal & $1 \mathrm{~min}$ \\
\hline First rate & $10^{\circ} \mathrm{C} \mathrm{min}^{-1}$ up to $100^{\circ} \mathrm{C}$ \\
\hline Second rate & $4^{\circ} \mathrm{C} \mathrm{min}-1$ up to $285^{\circ} \mathrm{C}$ \\
\hline Isothermal & $15 \mathrm{~min}$ \\
\hline
\end{tabular}

Under the optimal conditions, SIM method was selected as the highest sensitive mode in polycyclic aromatic hydrocarbons determinations so that GC-MS was able to determine these species in ppt levels. In this study, a series of standard solutions $\left(15,25,50,100 \mathrm{~nL}^{-1}\right)$ prepared by using an internal standard and injected into the column. Response characteristics of 16 polycyclic aromatic hydrocarbons compounds are given in Table-2.

The mass chromatograms of the blank and standard solutions have been also shown in Fig. 1a and $1 \mathrm{~b}$.
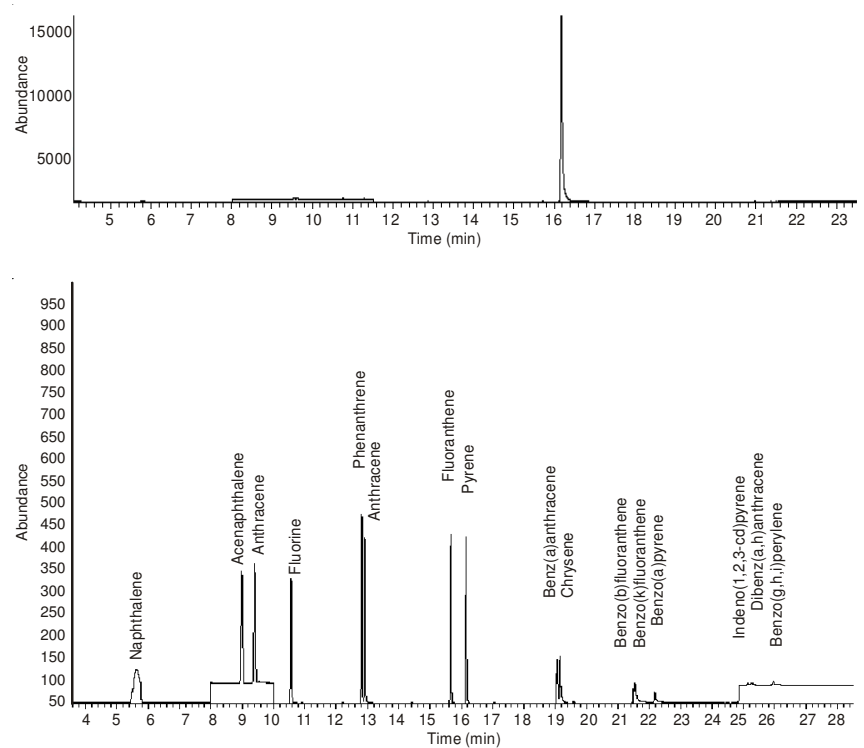

Fig. 1. Mass chromatograms of (a) blank (b) $15 \mathrm{ng} \mathrm{L}^{-1}$ standard solution of the investigated polycyclic aromatic hydrocarbons

In this study, pyrene was marked by deuterium and used as internal standard because of its inherent properties such as 


\begin{tabular}{|c|c|c|c|c|}
\hline \multicolumn{5}{|c|}{$\begin{array}{c}\text { TABLE-2 } \\
\text { RESPONSE CHARACTERISTICS OF SEVERAL POLYCYCLIC HYDROCARBON } \\
\text { AROMATICS POLYCYCLIC AROMATIC HYDROCARBONS }\end{array}$} \\
\hline Compound & R.T. & Response & Con unit & QION \\
\hline Chrycene & 40.64 & 212 & 40.64 & 228 \\
\hline Benzo(b)fluoranthene & 44.21 & 334 & 44.21 & 252 \\
\hline Benzo(k)fluoranthene & 50.11 & 362 & 50.11 & 252 \\
\hline Benzo(a)pyrene & 42.23 & 281 & 42.23 & 252 \\
\hline Indeno(1,2,3-cd)pyrene & 45.93 & 230 & 45.93 & 276 \\
\hline Dibenz(a,h)anthracene & 46.04 & 232 & 46.04 & 278 \\
\hline Benzo(g,h,i)perylene & 45.72 & 287 & 45.72 & 276 \\
\hline Benz(a)anthracene & 49.50 & 398 & 49.50 & 228 \\
\hline Anthracene & 56.76 & 919 & 56.76 & 154 \\
\hline Fluorine & 7.212 & 1067 & 57.91 & 166 \\
\hline Phenanthrene & 8.950 & 1520 & 59.03 & 178 \\
\hline Anthracene & 9.065 & 1039 & 60.10 & 178 \\
\hline Fluoranthene & 12.294 & 1073 & 57.47 & 202 \\
\hline Pyrene & 13.106 & 1042 & 59.28 & 202 \\
\hline Naphthalene & 4.403 & 2115 & 54.25 & 128 \\
\hline Acenaphthalene & 6.300 & 1683 & 57.73 & 152 \\
\hline
\end{tabular}

good solubility, suitable retention time and lack of any ionic interference. To plot a calibration curve, standard mixture solutions of 16 polycyclic aromatic hydrocarbons in the range of 15 to $200 \mathrm{ng} \mathrm{L}^{-1}$ were prepared. The standard solutions after preparing and extraction introduced to GC-MS. For each standard solution, all stages repeated 3 times and each point of calibration curve resulted of average of three successive measurements. The calibration curve for each analyte plotted based on the ratio of analyte peak area to internal standard peak area. Fig. 2 shows calibration graphs of some polycyclic aromatic hydrocarbons compounds.

Detection and quantification limits for each analyte determined based on $3 \sigma$ and $10 \sigma$, respectively. The precision of method resulted based on its reproducibility on three successive analyses. The accuracy in all investigated samples was less than $5 \%$ as a result of reliability of the developed method. The averaged amounts of LOD and LOQ were obtained 4.5 and $15 \mathrm{ng} \mathrm{L}{ }^{-1}$, respectively. The dynamic ranges were nearly 40 times the detection limit. In order to study precision and accuracy of the developed method, the obtained results were compared with those from the method number 610 US.EPA.

Several real samples were prepared from water effluents including Jalalieh, Kan, Tehranpars 1, Tehranpars 2 and Sohanak water treatment plants with several water storage tanks (related to Tehran province water distribution). After pretreating of the samples, the solutions were injected to the inlet of GC-MS column by a Hamilton microliter syringe. Fig. 3 shows mass chromatogram of Jalalieh effluent after treating the sample as mentioned in the procedure.

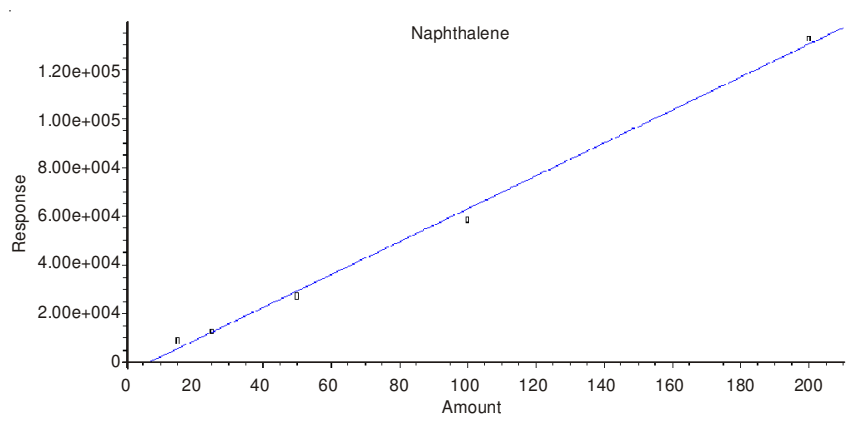

(a)

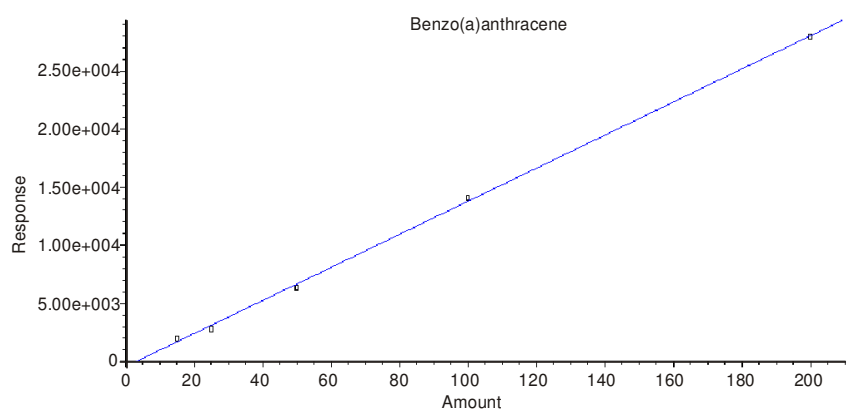

(c)

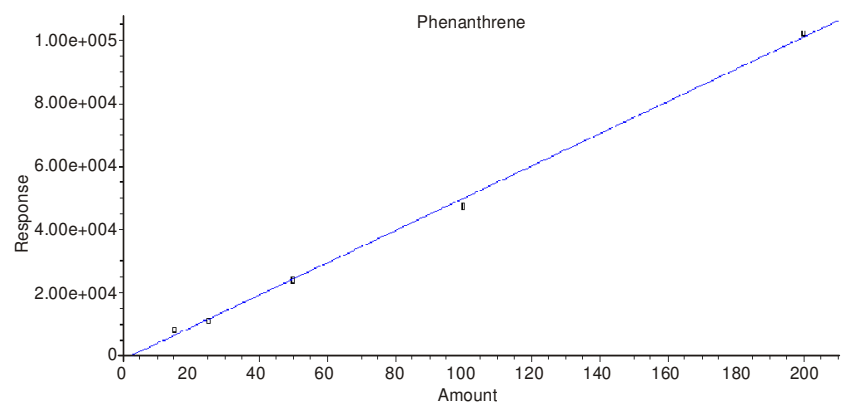

(b)

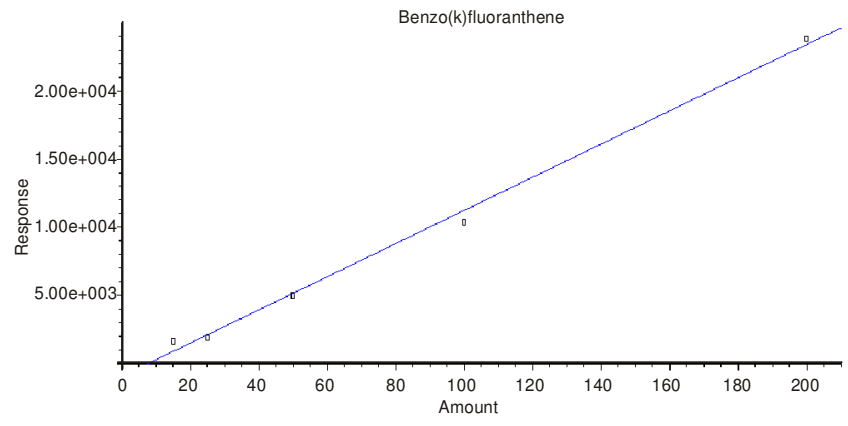

Fig. 2. Calibration graph of $15 \mathrm{ng} \mathrm{L^{-1 }}$ of (a) naphthalene, (b) phenanthrene, (c) benzo(a)anthracene, (d) benzo(k)fluoranthene 
TABLE-3

PERMITTED LIMITS OF BENZO(A)PYRENE IN DRINKING WATER

\begin{tabular}{|c|c|c|c|c|c|}
\hline \multirow{2}{*}{$\begin{array}{c}\text { Quality guideline } \\
\text { polycyclic aromatic hydrocarbons }\end{array}$} & \multicolumn{2}{|c|}{ EPA (ppb) } & \multirow{2}{*}{$\begin{array}{l}\text { WHO } \\
(\mathrm{ppb})\end{array}$} & \multirow{2}{*}{$\begin{array}{l}\text { Wisconsin } \\
(\mathrm{ppb})\end{array}$} & \multirow{2}{*}{$\begin{array}{l}\text { Iranian national standarc } \\
\text { (St No. 1053, ppb) }\end{array}$} \\
\hline & MCL* & MCLG* & & & \\
\hline Benzo(a)pyrene & 0.2 & $<0.1$ & 0.7 & 0.2 & 0.2 \\
\hline
\end{tabular}

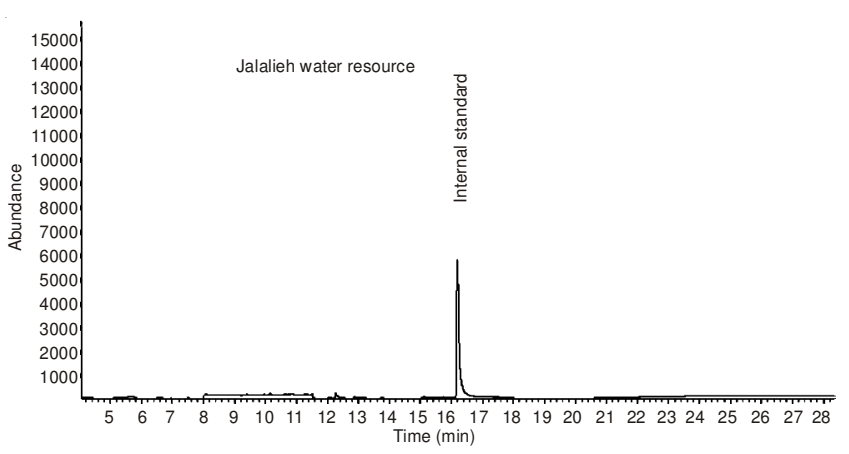

Fig. 3. Mass chromatogram of water effluent of Jalalieh resource

The chromatograms show that concentration of 16 polycyclic aromatic hydrocarbons compounds in all samples are lower than permitted limits for drinking water based on Iranian national standard (1053), WHO, US.EPA ${ }^{17}$ and American Wisconsin standards ${ }^{18}$. Permitted limits of benzo(a)pyrene for each of standards are given in Table- 3 .

To avoid from pollution of water resources, some recommendations by our research team have been considered. All operators should avoid from using pitchy tanks and pipe lines to prevent adding polycyclic aromatic hydrocarbons to water in treatment and distribution stages. Introducing several special compounds as indicator compounds for present of polycyclic aromatic hydrocarbons in water (some researchers just introduce benzo(a)pyrene as an indicator). Preparing executive instruction to prevent water resources from polycyclic aromatic hydrocarbons pollution, especially for surface waters. Double layering of storage tanks to prevent gasoline leakage to groundwater resources. Training the gas station personals is necessary. Controlling the oil pipe lines and covering them efficiently underground.

\section{Conclusion}

In the present work, it was not necessary to perform any treatment of test solutions with derivatization or masking agents and simultaneous determination of the investigated 16 polycyclic aromatic hydrocarbons was conveniently carried out. Besides, the method was free from presence of interferences such as halogenated and unsaturated hydrocarbons. Here, various instrumental conditions were studied and optimized. Under the optimal conditions, the $3 \sigma$ averaged detection limit was $4.5 \mathrm{ng} \mathrm{L}^{-1}$. At $15 \mathrm{ng} \mathrm{L}^{-1}$ the relative standard deviations $(n=4)$ was less than $2.7 \%$. The method was also ideally suited for determination of the investigated polycyclic aromatic hydrocarbons in drinking water.

Mass chromatograms of several real samples including water effluents supplied form Jalalieh, Kan, Tehranpars 1, Tehranpars 2 and Sohanak water treatment plants with several water storage tanks (related to Tehran province water distribution) revealed that polycyclic aromatic hydrocarbons concentration levels were fortunately less than permission limits according to different acceptable standards ${ }^{19}$.

\section{REFERENCES}

1. M. Zander, Physical and Chemical Properties of Polycyclic Aromatic Hydrocarbons, In Handbook of Polycyclic Aromatic Hydrocarbons. New York, pp. 1-25 (1983).

2. R.P. Wayne, Chemistry of the Atmospheres, Oxford University Press, Oxford, edn 3, pp. 1-50 (2000).

3. World Health Organization, Guidelines for Drinking-Water Quality, Recommendations, Geneva, Switzerland, edn 3, Vol. 1 (2004).

4. E. Manoli and C. Samara, Trends Analyt. Chem., 18, 417 (1999).

5. United States Environmental Protection Agency (USEPA), Toxics Criteria for those States Not Complying with the Clean Water; Act section 303(c)(2)(B), 40 CFR 131.36, pp. 531-538 (1995).

6. Council of European Communities, Directives 75/440/EEC, 79/869/ EEC and 80/778/EEC (1998).

7. Council of the European Communities, Council Directive 98/83/EC of 3 November 1998 on the Quality of Water Intended for Human Consumption, Off. J. Eur. Commun., L330, pp. $32-54$ (1998).

8. R.G. Harvey, Polycyclic Aromatic Hydrocarbons, Wiley-VCH, New York, pp. 8-11 (1997).

9. B. Janoszka, I. Warzecha, U. Blaszczyk and D. Bodzek, Acta Chromatogr., 14, 115 (2004).

10. M. Norin and A.-M. Strömvaix, Environ. Technol., 25, 323 (2004).

11. L. Becker, G. Matuschek, D. Lenoir and A. Kettrup, Chemosphere, 42, 301 (2001).

12. T. Vo-Dinh, Talanta, 47, 943 (1998).

13. L. Pozzoli, S. Gilardoni, M.G. Perrone, G. De Gennaro, M. De Rienzo and D. Vione, Ann. Chim., 94, 17 (2004).

14. D. MacKay, W.Y. Shiu and K.C. Ma, Chemicals, Illustrated Handbook of Physical-Chemical. Properties and Environmental Fate for Organic, Vol. II, Lewis, Boca Raton, pp. 246-252 (1992).

15. L.E. Sverdrup, T. Nielsen and P.H. Krogh, Environ. Sci. Technol., 36, 2429 (2002).

16. L.A. Gundel, V.C. Lee, K.R.R. Mahanama, R.K. Stevens and J.M. Daisey, Atmos. Environ., 29, 1719 (1995).

17. United States Environmental Protection Agency (USEPA), Ground Water and Drinking Water, National Primary Drinking Water Regulations; http://www.epa.gov/safewater/contaminants/dw_contamfs/benzopyr. html (2006).

18. U.S. Wisconsin, Department of Health and Human Services; Public Health Service; Agency for Toxic Substances and Disease Registry. Division of Health Assessment and Consultation. Atlanta, Georgia 30333; http:// www.atsdr.cdc.gov (2004).

19. Iranian Standard and Industrial Research Institute (ISIRI). Available from http://www.isiri.org, (2012). 